\title{
Current Knowledge of Germline Genetic Risk Factors for the Development of Non-Medullary Thyroid Cancer
}

\author{
Kinga Hińcza ${ }^{1, *(D)}$, Artur Kowalik ${ }^{1(D)}$ and Aldona Kowalska ${ }^{2,3}$ (D) \\ 1 Department Molecular Diagnostics, Holycross Centre, 25-734 Kielce, Poland \\ 2 The Faculty of Health Sciences of the Jan Kochanowski University, 25-317 Kielce, Poland \\ 3 Endocrinology Clinic of Holycross Cancer Centre, 25-734 Kielce, Poland \\ * Correspondence: kinga.hin@wp.pl; Tel.: +48-4136-742-58
}

Received: 16 May 2019; Accepted: 25 June 2019; Published: 26 June 2019

check for updates

\begin{abstract}
The thyroid is the most common site of endocrine cancer. One type of thyroid cancer, non-medullary thyroid cancer (NMTC), develops from follicular cells and represents approximately $90 \%$ of all thyroid cancers. Approximately $5 \%-15 \%$ of NMTC cases are thought to be of familial origin (FNMTC), which is defined as the occurrence of the disease in three or more first-degree relatives of the patient. It is often divided into two groups: Syndrome-associated and non-syndromic. The associated syndromes include Cowden syndrome, familial adenomatous polyposis, Gardner syndrome, Carney complex and Werner syndrome. The hereditary factors contributing to the unfavorable course of FNMTC remain poorly understood; therefore, considerable effort is being expended to identify contributing loci. Research carried out to date identifies fourteen genes (DICER1, FOXE1, PTCSC2, MYH9, SRGAP1, HABP2, BRCA1, CHEK2, ATM, RASAL1, SRRM2, XRCC1, TITF-1/NKX2.1, PTCSC3) associated with vulnerability to FNMTC that are not related to hereditary syndromes. In this review, we summarize FNMTC studies to date, and provide information on genes involved in the development of non-syndromic familial non-medullary thyroid cancers, and the significance of mutations in these genes as risk factors. Moreover, we discuss whether the genetic polymorphism rs966423 in DIRC3 has any potential as a prognostic factor of papillary thyroid cancer.
\end{abstract}

Keywords: thyroid cancer; genetic abnormalities; genetic markers; molecular testing; oncogenic mutations

\section{Introduction}

Thyroid cancer is the most common malignant endocrine tumor, accounting for $1 \%-2 \%$ of all malignancies. In 2018, the World Health Organization (Global Cancer Statistics 2018: GLOBOCAN) reported 567,233 new cases of thyroid cancer, of which 41,071 resulted in death [1]. Thyroid cancer types are classified according to their histological characteristics (Figure 1) [2].

Malignant tumors of the thyroid gland can be derived from all types of cell present in this tissue. The vast majority are of follicular cell, parafollicular cell (C cell), and lymphoid cell origin, with tumors derived from other cell types occurring very rarely. Medullary thyroid carcinoma (MTC) develops from neuroendocrine $C$ cells, and can occur sporadically or as a familial condition. The familial form of MTC accounts for $20 \%-25 \%$ of cases, and is usually a component of multiple endocrine neoplasia (MEN) IIA or IIB [3]. Differentiated thyroid cancer (DTC) of follicular cell origin is also known as non-medullary thyroid cancer (NMTC) and represents approximately $90 \%$ of all thyroid cancers, and approximately $5 \%-15 \%$ of NMTC cases are thought to be of familial origin (FNMTC) [4]. 


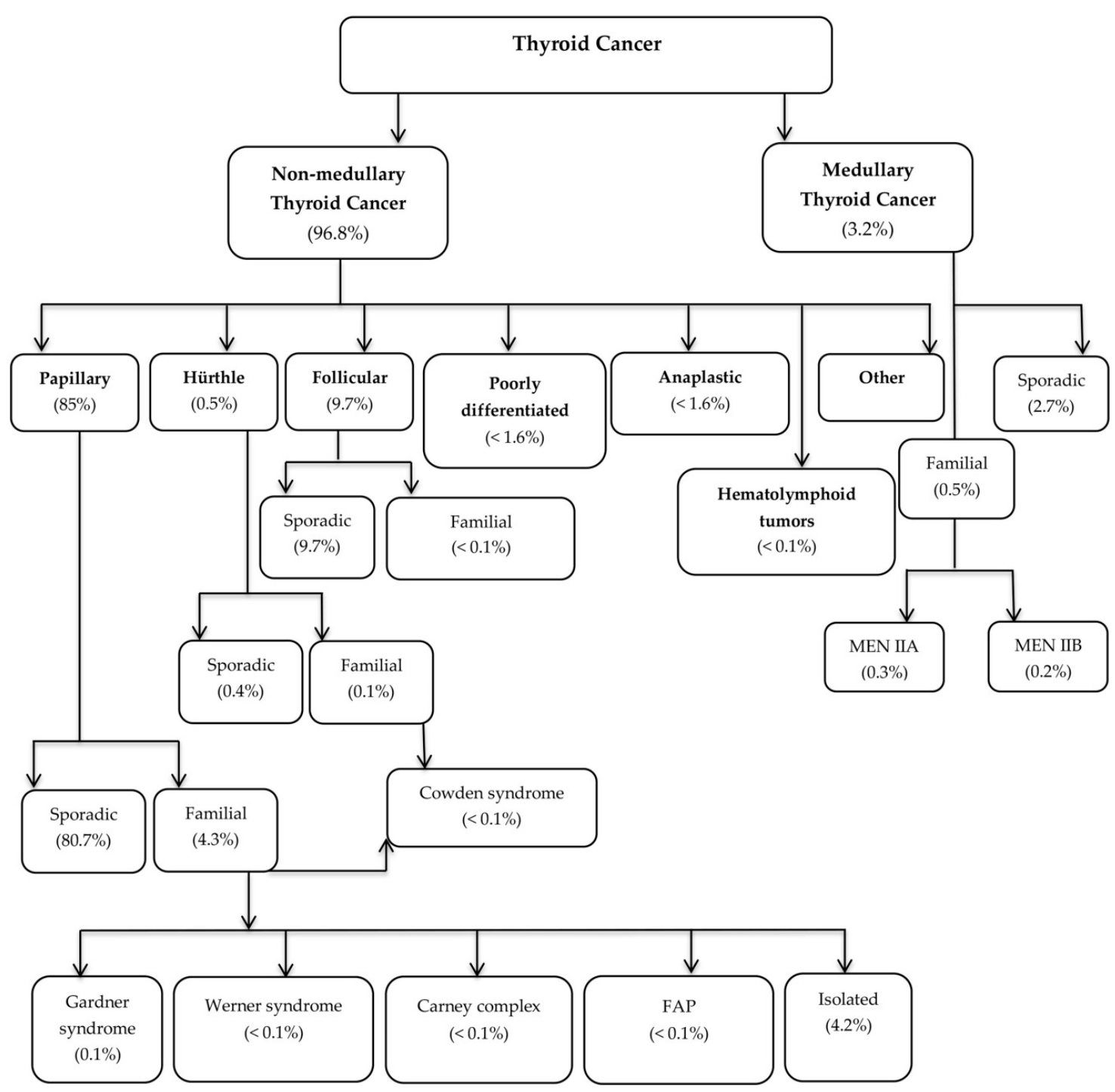

Figure 1. Thyroid Cancer classification (modified from Vriens et al. 2009).

FNMTC has an autosomal dominant pattern of inheritance, and the disease can occur as a result of either heterozygous or homozygous mutations. Moreover, polygenic inheritance is also plausible, particularly in those cases where only two family members are affected. Given the fairly frequent occurrence of NMTC, a definitive diagnosis of FNMTC must be made with caution, particularly in families where only two members are affected. FNMTC cases are characterized by high genetic heterogeneity (molecular heterogeneity), making it difficult to identify key molecular changes [5]. To date, genetic alterations with key roles in the development of each FNMTC subtype have yet to be fully characterized, representing a significant problem for screening and estimating the prognosis for individuals with the disease. Moses et al. (2011) report no significant differences in the type or number of somatic mutations (in BRAF, NRAS, KRAS, RET, and NTRK1) between cases with sporadic and familial NMTC [5].

The clinical characteristics of FNMTC are controversial. Some, but not all, authors have reported an earlier age of onset, higher incidence of multifocality and lymph node metastasis, and a more aggressive outcome with more frequent relapses, compared with sporadic disease $[5,6]$. Similar findings are reported by El Lakis et al. (2019) in FNMTC families with three or more affected members, suggesting a more aggressive disease with a greater rate of lymph node metastasis and an earlier age of onset, relative to the sporadic form. 
Further, based on their results, these authors suggest that surgical treatment should be more aggressive for patients with FNMTC [7]; however, a retrospective study by Pitoia et al. (2011) did not detect statistically significant differences in age at diagnosis, sex, tumor size, tumor stage or distant metastasis between patients with familial and sporadic NMTC. The only differences in the baseline characteristics observed between the two groups were in bilateral malignancy ( $38 \%$ vs. $24 \%$, respectively; $p=0.03)$, lymph node metastasis $(56.2 \%$ vs. $39 \%$, respectively; $p=0.01)$, and multicentricity (43\% vs. $28 \%$, respectively; $p=0.03$ ) [6]; however, Moses et al. (2011) suggest that patients with FNMTC present at a significantly younger age (an average of 5 years younger) than those with sporadic thyroid cancer, although no other statistically significant differences are detected. It is possible that the earlier diagnosis in individuals with FNMTC can be attributed to greater awareness and better access to preventive and screening tests [5]. Given the small differences in the clinical characteristics of patients with familial and sporadic NMTC, the therapeutic strategy for both diseases is the same $[8,9]$. FNMTC is defined based on the occurrence of disease in three or more first-degree relatives of the patient, and is often divided into two groups: Syndrome-associated and non-syndromic $[3,6]$.

\section{Syndromic FNMTC}

Inherited syndromes associated with an increased risk of FNMTC include the following: Familial adenomatous polyposis (FAP), Cowden syndrome, Werner syndrome, Carney complex, and papillary renal neoplasia (Table 1). Mutations in several genes are identified as responsible for these hereditary syndromes. Alterations in the APC gene are associated with FAP, and changes in PTEN, SDHB-D, PIK3CA, AKT1, KLLN, and SEC23B are responsible for Cowden syndrome. Mutations in PRKAR1 $\alpha$ cause Carney complex, while disturbances of the WRN gene signaling pathway are associated with development of Werner syndrome. Patients with the above-mentioned hereditary syndromes exhibit increased incidence of both thyroid cancer and other types of malignancy [10-24].

Table 1. Syndromic familial non-medullary thyroid cancer (NMTC). (Data from Yang et al. 2016, Vriens et al. 2009, and Griffith et al. 2016).

\begin{tabular}{|c|c|c|c|}
\hline Syndrome & Germline Genetic Alteration & Type of Thyroid Cancer & $\begin{array}{c}\text { Frequency of Thyroid } \\
\text { Lesions }\end{array}$ \\
\hline $\begin{array}{l}\text { Familial adenomatous } \\
\text { polyposis (FAP) }\end{array}$ & APC mutation & PTC & $1 \%-12 \%$ (usually women) \\
\hline Cowden's disease & $\begin{array}{c}\text { PTEN mutation } \\
\text { SDHB-D mutation, } \\
\text { PIK3CA mutation } \\
\text { AKT1 mutation } \\
\text { KLLN promoter methylation } \\
\text { SEC23B mutation }\end{array}$ & $\begin{array}{c}\text { PTC (classical and } \\
\text { follicular variant), FTC }\end{array}$ & $\begin{array}{c}10 \% \\
\text { Unknown }\end{array}$ \\
\hline Werner syndrome & WRN mutation & PTC, FTC, ATC & $\begin{array}{l}18 \% \text { of Japanese patients } \\
\text { develop thyroid carcinoma }\end{array}$ \\
\hline Carney complex & PRKAR1 $\alpha$ mutation & PTC, FTC & $3 \%$ \\
\hline Papillary renal neoplasia & Unknown & PTC & Unknown \\
\hline
\end{tabular}

\subsection{Familial Adenomatous Polyposis}

FAP is an autosomal dominant disease caused by inactivating mutations in the APC tumor suppressor gene on chromosome $5 \mathrm{q} 21$. In addition to numerous intestinal polyps, colon cancer, and other neoplasms, some patients with FAP are at increased risk of developing thyroid cancer. Of patients with FAP, $1 \%-12 \%$ develop thyroid carcinoma. Further, thyroid carcinoma associated with FAP is very often multifocal, and is more common among women and people under 30 years of age $[24,25]$. 


\subsection{Cowden Syndrome (PTEN Hamartoma Syndrome)}

Cowden syndrome is an autosomal dominant disorder characterized by hamartomatous changes and epithelial tumors of the breast, thyroid, kidney, colon and endometrium. PTEN gene mutations on chromosome 10q22-23 can cause this disease; however, in some cases, the cause is unknown, although these are also probably associated with a reduced PTEN protein suppressor activity. At least two thirds of patients with this syndrome are affected by thyroid disease, often before the age of 20 years. In addition, approximately $10 \%$ of patients with Cowden syndrome will develop thyroid cancer in their lifetime, usually papillary thyroid cancer (PTC) or follicular thyroid carcinoma (FTC) histological types. In addition, a comparison of the numbers of thyroid nodules show that patients with thyroid cancer from the general population have significantly fewer than those with Cowden syndrome $[24,25]$.

\subsection{Werner Syndrome}

Werner syndrome is an autosomal recessive disorder caused by mutations in the WRN gene on chromosome 8p11.1-21.1. This syndrome is associated with premature aging, short stature, and several neoplasms, including meningiomas, soft tissue sarcomas, and thyroid carcinoma.

Werner syndrome is particularly common in Japan, and Japanese patients with this condition are more likely to develop thyroid cancer than Caucasians with the syndrome. The histologic types of thyroid cancer detected in patients with Werner syndrome include FTC, PTC, and occasionally anaplastic thyroid cancer [24]. Approximately $18 \%$ of Japanese patients with Werner syndrome develop thyroid cancer [24,25].

\subsection{Carney Complex}

Carney complex is most commonly due to a mutation of the PRKAR1A gene on chromosome 17q22-24; however, some cases are linked with an unknown gene at 2p16. Carney complex is an autosomal dominant disease, in which patients have spotty skin pigmentation and an increased risk of cardiac myxomas, and develop a variety of tumors involving endocrine organs; almost $60 \%$ of patients with this condition develop tumors of the thyroid gland. Histologically, most nodules are benign adenomas; however, approximately $3 \%$ of patients will develop thyroid carcinoma, including PTC and FTC $[24,25]$.

\subsection{Papillary Renal Neoplasia (PRN) and Other Rare Syndromes Associated with NMTC}

PRN is associated with the occurrence of malignant renal tumors. The genetic cause of PRN is not yet known; however, an unidentified gene at the chromosomal locus 1q21 is likely responsible for this autosomal dominant disease associated with papillary renal carcinoma and thyroid cancer. A PTC phenotype associated with PRN is extremely rare, and is only described in one family to date [24].

Several other hereditary conditions, including McCune-Albright, Peutz-Jeghers, and Louis Bar syndromes, are also associated with the development of NMTC; however, their importance is not fully understood.

\section{Non-Syndromic FNMTC}

\subsection{GWAS of Thyroid Cancer}

The genome-wide association study (GWAS) approach is emerging as a popular method to identify genetic factors involved in complex diseases [26]. In this review, we describe the most common germline variants associated with thyroid cancer that have been detected by GWASs. Several GWASs were conducted in patients of European descent, and some single-nucleotide polymorphisms (SNPs) are reported to be associated with thyroid cancer risk; however, only a subset of these variants have been confirmed in different populations, including Japanese, Chinese, Polish, and British, by targeted genotyping methods [27]. 
The first GWAS of thyroid cancer was reported in 2009. The most significant variants identified as germline candidate risk factors were SNPs located close to gene loci, including FOXE1, NKX2-1, DIRC3, XRCC1, XRCC3, TITF-1, and TITF-2, in patients of European descent. Signals at the VAV3, INSR, MRSB3, FHIT, SEPT11, and SLC24A6 loci were only identified in Koreans [28]. These findings support the possibility of variations in the genetic factors contributing to thyroid cancer risk among different populations. Overall, the potential role of these various polymorphisms in the development of NMTC requires further characterization, and the molecular background of these polymorphisms has yet to be elucidated [26].

Additional studies assess five SNPs (rs965513, rs944289, rs116909374, rs2439302, and rs966423) in 1216 patients with PTC and 1416 controls, along with the expression of seven genes (PTCSC3, MBIP, NKX2-1, FOXE1, DIRC3, PTCSC2, and NRG1) located near to the genotyped SNPs in 73 paired PTC tumor and adjacent normal tissues. The study revealed associations between risk alleles of rs965513 and rs2439302 and more aggressive disease (larger tumor size, extrathyroidal expansions, and multifocality status). This study proved that germline variants predispose to PTC development and poor clinical outcome. In addition, expression levels of MBIP and NKX2-1 (important genes in thyroid organogenesis) correlate with $\mathrm{T}$ stage and N1 stage, respectively [29]. Japanese researchers studied five cancer related SNPs [rs966513 (9q22.33, FOXE1), rs944289 (14q13.3, PTCSC3), rs2439302 (8p12, NRG1), rs1867277 (9q22.23, FOXE1), and rs6983267 (8q24, POU5F1B)] in a cohort of 959 cases with follicular adenoma (FA), 535 cases with PTC, and 2766 controls. They detected significant associations between FA and rs944289 ( $p=0.002)$ and rs2439302 ( $p=0.033)$. Furthermore, the following SNPs were associated with PTC: rs965513 $\left(p=4.21 \times 10^{-4}\right)$, rs944289 $(p=0.003), \operatorname{rs} 2439302(p=0.003)$, and rs1867277 $\left(p=1.17 \times 10^{-4}\right.$. These authors also noted a significant correlation between rs2439302 genotype and lower expression of NRG1 in normal thyroid and PTC tumor tissue. This work highlighted a common risk SNP (rs944289) for benign and malignant tumors of the thyroid [30].

The $S M A D$ family member 3 gene (SMAD3) shows higher expression in the thyroid than in the majority of other tissues, supporting a potential role for this factor in predisposition to thyroid cancer. Recently, Wang et al. (2018) revealed functional roles for two single-nucleotide polymorphisms (rs17293632 and rs4562997), located in separate introns of SMAD3, which maps to the 15q22 locus, and had previously been identified by GWAS as associated with PTC. Further, these authors investigated the downstream mechanisms by which alterations of SMAD3 contribute to thyroid cancer susceptibility [31].

\subsection{Genes and loci Associated with Non-Syndromic FNMTC}

Hereditary factors contributing to the unfavorable course of FNMTC remain poorly understood; therefore, considerable efforts are being made to identify contributing loci. Understanding the molecular risk factors and prognosis of this disease would allow the evaluation of patient prognosis, which would significantly assist in managing the treatment and methods of monitoring patients. Research carried out to date has identified fourteen genes associated with a vulnerability to the development of FNMTC not related to hereditary syndromes (Table 2). In addition, seven chromosomal loci (1p13.2-1q21, 1q21, 2q21, 6q22, 8p23.1-p22, 8q24, and 19p13.2) involved in FNMTC susceptibility have been mapped, where the causal genes remain to be identified [24,32]. 
Table 2. Genes involved in the development of non-syndromic familial non-medullary thyroid cancers and the significance of the mutations in these genes as risk factors.

\begin{tabular}{cccc}
\hline Gene & Type of Thyroid Cancer & Risk Factor & Reference \\
\hline DICER1 & PTC & + & $\begin{array}{c}\text { Rutter et al. (2016) [33] } \\
\text { Wasserman et al. (2018) [34] }\end{array}$ \\
\hline FOXE1,PTCSC2,MYH9 & PTC and FTC & + & Pereira et al. (2015) [9] \\
\hline SRGAP1 & PTC & + & He et al. (2013) [35] \\
\hline HABP2 & PTC & +- & $\begin{array}{c}\text { Gara et al. (2015) [36] } \\
\text { Alzahrani et al. (2016) [37] } \\
\text { Kowalik et al. (2017) [38] }\end{array}$ \\
\hline BRCA1 & PTC & + & Wójcicka et al. (2014) [39] \\
\hline CHEK2 & PTC & + & $\begin{array}{c}\text { Wójcicka et al. (2014) [39] } \\
\text { Siołek et al. (2015) [40] }\end{array}$ \\
\hline ATM & PTC and DTC & + & $\begin{array}{c}\text { Dombernowsky et al. (2008) [41] } \\
\text { Akulevich et al. (2009) [42] } \\
\text { Gu et al. (2014) [43] }\end{array}$ \\
\hline RASAL1 & FTC & + & Ngeow et al. (2014) [44] \\
\hline SRRM2 & PTC & + & Tomsic et al. (2015) [45] \\
\hline XRCC1 & PTC & $+/-$ & Ryu et al. (2011) et al. [46] \\
\hline TITF-1/NKX2.1 & PTC & $+/-$ & $\begin{array}{c}\text { Ngan et al. (2009) [47] } \\
\text { Cantara et al. (2010) [48] }\end{array}$ \\
\hline PTCSC3 & PTC & $+/-$ & Jendrzejewski et al. (2012) [49] \\
\hline
\end{tabular}

PTC, papillary thyroid cancer; FTC, follicular thyroid cancer; DTC, differentiated thyroid cancer.

\subsubsection{DICER1}

Changes in the DICER1 gene have been identified as potentially influencing the development of NMTC. DICER1 maps to the chromosome 14q32 locus, and the DICER1 protein is a member of the ribonuclease (RNase) III family that cleaves small non-coding RNA (miRNA) precursors to generate mature miRNAs, which regulate gene expression post-transcriptionally. Pathogenic germline DICER1 mutations cause DICER1 syndrome, which is associated with a predisposition to various tumors and is characterized by multinodular goiter (MNG), particularly in children.

Wasserman et al. (2018) showed that, in patients with PTC, changes in the DICER1 gene are more frequent in diagnoses in children than in adults; however, they did not influence the aggressiveness of the disease course [34]. Further, Rutter et al. (2016) suggested that patients with the germline change c.5441C $>$ T (p.S1814L) in DICER1 are at an increased risk of MNG and DTC. More frequent screening may be warranted in DICER1 families who have a first-degree relative with DTC [33].

\subsubsection{FOXE1, PTCSC2, MYH9}

Forkhead box E1 (FOXE1), also known as thyroid transcription factor 2, is highly expressed in thyroid follicular cells, and is essential for thyroid gland formation and development [50]. Recently, FOXE1 has been implicated in numerous types of cancer, including PTC [51]. Studies conducted on the Icelandic population and people of European origin indicate that the simultaneous occurrence of two polymorphic changes (rs944289 and rs965513) in the vicinity of the gene encoding FOXE1 increases the risk of PTC and FTC development [9]. Allele [A] of rs 965513 was identified as a risk factor predisposing to PTC at the 9q22 locus by GWAS. Further studies discovered a novel long intergenic noncoding RNA gene within the 9q22 locus, named papillary thyroid cancer susceptibility candidate 2 (PTCSC2). Allele [A] of rs 965513 is correlated with low expression levels of the PTCSC2 unspliced transcript, FOXE1 (implicated in thyroid development), and TSHR, in unaffected thyroid tissue, but not in PTC tumors. By contrast, PTCSC2 is down-regulated in PTC. Levels of the PTCSC2 unspliced transcript are associated with age and chronic lymphocyte thyroiditis [52]. Further studies conducted on patients with PTC and controls narrowed the 9q22 locus to an approximately 33-kb linkage disequilibrium block, containing rs965513. In this block at least three regulatory elements were detected that function 
as enhancers, and which harbor additional SNPs (rs7864322, rs12352658, rs7847449, and rs10759944). Variants of these SNPs impact differential enhancer and/or transcription factor binding activities. These elements interact with a promotor region shared by PTCSC2 and FOXE1. PTCSC2 has tumor suppressor functions by inhibiting PTC cell motility and invasion through the suppression of S100A4 transcription [53]. Lately, additional studies have revealed that myosin-9 (MYH9) binds to the lncRNA gene, PTCSC2, and suppress the expression of FOXE1, which regulates the p53 pathway in thyroid cells. This mechanism of regulation underlies the predisposition to PTC in carriers of the rs 965513 SNP [54].

\subsubsection{PTCSC3}

Further work leads to the detection of the long noncoding RNA, PTC susceptibility candidate 3 (PTCSC3), which is located downstream of rs944289 at 14q13.3. Interestingly, PTCSC3 expression is downregulated in PTC thyroid tumor tissue, and strongly suppressed by the T allele of rs944289. This SNP is located in a binding site for CCAAT/enhancer binding proteins (C/EBP) $\alpha$ and $\beta$, which activate the PTCSC3 promotor. In silico analysis predicted that the T risk allele destroys the binding site, thereby reducing any PTCSC3 expression. Restoration of PTCSC3 expression in thyroid cell lines inhibits cell growth, suggesting that this protein has a tumor suppressor function [49].

\subsubsection{SRGAP1}

He et al. (2013) assess the relationship between the SRGAP1 gene and susceptibility to PTC. Their results indicate the importance of two missense variants (c.447A $>C$ and c.823G $>A$ ) in the SRGAP1 gene in increasing PTC invasiveness. These variants influence CDC42 protein activity, since SRGAP1 regulates a small G-protein that acts as a signal transduction convergence point in intracellular signaling networks, mediates multiple signaling pathways and contributes to tumorigenesis $[35,55]$.

\subsubsection{HABP2}

Gara et al. (2015) describe the gene variant G534E in $H A B P 2$, which maps to chromosome 10q25.3, the overexpression of which can be detected in tumor cells from patients with FNMTC, relative to cells from the healthy regions of the thyroid gland, or patients with sporadic NMTC [36].

By contrast, Alzahrani et al. (2016) studied a Middle Eastern population with FNMTC, and did not detect any germline changes in the HABP2 gene [37]. Similarly, no association is detected between this variant and NMTC risk across all histological subtypes (PTC, FTC, and Hürthle cell) in a study reported by Sahasrabudhe et al. (2015) [56]. Kowalik et al. (2017) analyze the incidence of the c.1601G>A variant of $H A B P 2$ in a Polish population, consisting of 326 cases with PTC and 400 controls. Their results indicate no significant difference in the frequency of the c.1601G $>$ A variant in the Polish population at an increased risk of PTC development; the variant was more common in control individuals (4.7\%; $19 / 400)$ than in patients with PTC $(3.7 \% ; 12 / 326)$. In addition, no correlations were identified between the G534E variant and clinical and pathological disease features, response to primary treatment, or clinical status [38].

\subsubsection{DNA Double-Strand Break Repair Genes (ATM-BRCA1-CHEK2)}

There is evidence to suggest that ionizing radiation directly influences the risk of differentiated thyroid and breast cancers. Ionizing radiation primarily promotes carcinogenesis via its ability to induce DNA double-strand breaks, which pose a challenge for cellular DNA repair pathways. The functionality of the ATM-BRCA1-CHEK2 DNA repair pathway is affected by polymorphisms and mutations within these genes, and these underlie inefficient DNA repair, leading to tumorigenic changes within cells. In mammalian cells, DNA double-strand breaks activate the ATM kinase, which phosphorylates and activates CHEK2. Subsequently, CHEK2 phosphorylates BRCA1 and triggers DNA repair or, if this fails, leads to apoptosis [39]. Wójcicka et al. (2014) conducted a study to clarify the roles as factors predisposing to PTC of the following polymorphic changes: ATM, D1853N; BRCA1, 
E1038G; and CHEK2, I157T. The authors demonstrate significant associations of rs17879961 in CHEK2 and rs16941 in BRCA1 with susceptibility to PTC. By contrast, no such relationship is detected for rs1801516 in ATM [39]. Siołek et al. (2015) detect a statistically significant correlation between carrier status for the CHEK2 gene mutations 1100delC, IVS2 + 1G>A, del5395, and I157T and increased risk of PTC. To characterize the association of CHEK2 mutations with thyroid cancer, they genotyped 468 unselected patients with PTC and 468 (matched) cancer-free controls. A CHEK2 mutation was detected in 73 of the 468 (15.6\%) unselected patients with PTC, relative to 28 of $460(6.0 \%)$ age- and sex-matched controls. Overall, their results suggest that CHEK2 mutations predispose to papillary thyroid cancer and increase the risk of PTC co-occurring with breast cancer [40]. Further, Akulevich et al. (2009) and Dombernowsky et al. (2008) suggest that polymorphic changes in the ATM gene increase the risk of sporadic PTC and DTC in the Caucasian population [41,42]. Gu et al. (2014) analyze the relationship between polymorphic changes in ATM and an increased risk of PTC in the Asian population. The results indicate that, of the four polymorphisms studied (rs664677, rs373759, rs4988099, and rs189037), only rs373759 was associated with an increased risk of PTC development [43].

\subsubsection{RASAL1}

The protein encoded by RASAL1 is member of the GAP1 family of GTPase-activating proteins. Acting as a suppressor of oncogenic RAS function, RASAL1 protein enhances the weak, intrinsic GTPase activity of RAS proteins, resulting in an inactive GDP-bound form of RAS, thereby allowing control of cellular proliferation and differentiation [57]. Xing et al. (2013) study how alternative RAS signaling-related genes affect thyroid tumorigenesis. Compared with normal human thyroid tissue, the RAS GTPase-activating protein gene, RASAL1, is commonly, but differentially, somatically mutated or hypermethylated in thyroid cancers. Sequence analysis of thyroid cancer samples for somatic mutations in RASAL1 predominantly identify mutations in FTC tumors [58]. Given these recent findings, Ngeow et al. (2014) explore the prevalence of germline RASAL1 mutations in a subset of patients with Cowden syndrome who have thyroid cancer. They genotyped 155 patients for germline RASAL1 mutations, among which 39 had PTEN mutations and 116 did not. Of the 116 patients, 53 (46\%) had either FTC or follicular-variant PTC, 54 (47\%) had PTC, 7 (6\%) had Hürthle cell thyroid cancer, and 1 had ATC, while among the 39 patients, one-third (13/39) had FTC or follicular-variant PTC.

Among all 155 patients, RASAL1 germline alterations suspected to be deleterious were detected in two patients. Interestingly, both were patients without PTEN mutations who had FTC and had the same pathogenic missense variant in RASAL1, R328W, in exon 11. Ngeow et al. (2014) did not detect any deleterious germline RASAL1 alterations in patients with thyroid cancer with simultaneous mutations in PTEN. Based on these findings, germline mutations in the RASAL1 gene may be a risk factor for the development of FTC in PTEN mutation-negative patients and those with Cowden syndrome [44].

\subsubsection{SRRM2}

Tomsic et al. (2015) use a combination of genetic methods and detect mutation in a single candidate gene, SRRM2. SRRM2 is a splicing factor, and promotes exon enhancer-dependent splicing by forming multiple critical interactions with factors bound directly to pre-mRNA. Analysis leading to identify a variant c.1037C > T (S346F) in the splicing gene SRRM2, was making it a leading candidate mutation contributing to the development of PTC. Authors speculate that the mutated protein affects the splicing of at least one of the genes specifically expressed in the thyroid or involved in a thyroid-specific pathway, thereby leading to PTC formation [45].

\subsubsection{XRCC1}

XRCC1 encodes a protein with an important role in the base excision repair (BER) pathway for single-strand DNA break repair and maintenance of genetic stability. Ryu et al. (2011) perform a genetic analysis of two known polymorphisms of the XRCC1 gene, R194W and R399Q, in a Korean sample. The frequencies of the XRCC1 R194 genotype are 38.7\% in the cancer group and $49.0 \%$ in the 
control group, while those of XRCC1 R399 genotype are 15.3\% and 19.0\%, respectively. There are no sex- or age-associated statistically significant differences with regard to the risk of PTC for the two XRCC1 polymorphisms. The molecular consequences of the two non-synonymous polymorphisms in XRCC1 analyzed by Ryu et al. (2011) are not yet fully understood [46].

\subsubsection{TITF-1/NKX2.1}

TITF-1/NKX2.1 comprises two exons that encode a 42-kDa thyroid transcription factor-1, TTF-1, which activates the transcription of thyroglobulin, thyroperoxidase, and the thyrotropin receptor [24]. Ngan et al. (2009) examine DNA extracted from blood samples from 20 patients with MNG/PTC, 284 with PTC, and 349 control subjects, for mutations in TITF-1/NKX2.1. Targeted DNA sequencing reveals a germline TITF-1/NKX2.1 A339V mutation in four patients with PTC and a history of MNG. Of these four patients, two have a positive family history of PTC, and the pattern of inheritance was autosomal dominant in both families. In the first family, three cases carry this germline mutation, each of which was affected with PTC and MNG, MNG, or PTC with MNG. In the second family, two members have this germline mutation, both of whom present with PTC and MNG or MNG [47]. Cantara et al. (2010) analyze 63 PTC patients for the presence of the A339V mutation in TITF-1/NKX2.1. They suggest that the mutation correlates with a predisposition to the development of a familial form of thyroid cancer; however, their results show that all of the 63 patients with PTC tested have the wild-type allele at this locus, providing no support for a role for the A339V mutation in FNMTC development [48]; hence, the utility of the A339V TTF-1 mutation as a susceptibility gene for the development of PTC remains uncertain.

\section{Molecular Analysis of Germline Changes as Potential Prognostic Factors in PTC}

Over the past five decades, the mortality rate for patients with PTC has significantly decreased. Moreover, patients with PTC have a very good prognosis, since approximately 95\% survive for 10 years. The vast majority of patients with PTC are diagnosed with benign tumors, while an analysis of autopsy results, focused on papillary thyroid microcarcinoma, finds that this condition could be detected in $30 \%$ of people who die of other causes.

Hence, the main clinical challenge regarding PTC is to avoid overdiagnosis and any overtreatment of people with low-grade disease or benign thyroid nodules. By contrast, rapid identification of aggressive cases is vital, as the cause of death is often metastasis $[59,60]$. The poor understanding of predictive germline factors is a very serious problem, and knowledge of these would allow an estimation of patient prognosis before treatment. Unlike lesions, characteristic tumor gene polymorphisms can be determined from patient peripheral blood samples long before surgery. Świerniak et al. (2016) analyze the relationship between the genetic polymorphism rs966423 in DIRC3 and the mortality in patients diagnosed with DTC. Their results indicate a relationship between an increased risk of death during the course of DTC and the prognostic factors, such as the rs966423 variant in DIRC3, male sex, age $>45$ years, tumor size $>30 \mathrm{~mm}$, angioinvasion, lymph node metastasis (pN1b), distant metastasis (M1), and stage IV disease [61]. Wei et al. (2015) analyze the relationship between specific polymorphisms (rs944289, rs965513, rs966423, and rs2439302) and clinical and pathological factors in patients with PTC. They also find that rs966423 in DIRC3 is associated with tumor invasion and multifocality, and is a potential prognostic factor [62].

\section{Significance of microRNA Polymorphisms in NMTC}

Small noncoding RNA molecules (microRNAs) participate in a variety of biological processes and function as suppressors to regulate mRNA stability. SNPs within microRNA sequences may change their properties, and such SNPs are involved in the tumorigenesis of diverse malignancies, with aberrant levels of miRNAs observed in PTC cases compared with healthy controls. Further, microRNAs can change the formation and function of the thyroid tissues by regulating gene expression [63]. 


\section{1. $r s 2910164$}

One of the most common miRNA SNPs to be reported in connection with PTC risk is rs2910164 (miR-146a) [63]. In an association study of 608 patients with PTC and 901 controls, Jazdzewski et al. (2008) show that the GC heterozygous state at rs2910164 is associated with an increased risk of acquiring PTC (odds ratio $=1.62, p=0.000007$ ), whereas both homozygous states (GG and CC) are protective, with odds ratios of 0.42 for the CC genotype ( $p=0.003)$ and 0.69 for the GG genotype $(p=0.0006)$ [64]. Dong et al. (2015) investigate the association between the miRNA variants, rs2910164 (miR-146a), rs4919510 (miR-608), rs79402775 (miR-933), and rs2292832 (miR-149), and the PTC risk in a Han Chinese population. No significant association is detected between the miR-146a polymorphism and the PTC risk under the four established genetic models. Similarly, neither miR-608 nor miR-933 variants confer PTC risk under these genetic models; however, the miR-146a polymorphism is significantly correlated with an elevated risk of PTC under the heterozygous, homozygous, dominant and allelic models, based on comparisons of genotype distribution between PTC cases and healthy controls. These authors also conduct a meta-analysis, to summarize the overall effect of the miR-146a SNP on PTC risk. Nevertheless, Dong et al. (2015) report no significant association between miR-146a polymorphisms and PTC risk under any genetic model [63].

\section{2. $r s 11077$}

Exportin 5 (XPO5) is an essential specific nuclear transport factor, involved in the completion of pre-miRNA transport into the cytoplasm from the nucleus. Overexpression of XPO5 is thought to lead to a higher activity of miRNAs, while a loss of XPO5 expression inhibits the nuclear export of pre-miRNAs. Wen et al. (2017) compares XPO5 expression levels in thyroid cancer and normal tissues, and then evaluates and quantifies the association between XPO5 miR-SNPs and any susceptibility to thyroid cancer in a Chinese population. Expression of XPO5 was significantly lower in thyroid cancer than in normal tissues. Further, the XPO5 rs11077 TG/GG genotype is associated with higher susceptibility to thyroid cancer. Moreover, the TG/GG genotypes correspond to lower expression of XPO5 mRNA.

These results suggest that the XPO5 miRNA-SNP, rs11077, is a potential biomarker for thyroid cancer prediction, via its functional impact upon XPO5 expression [65]; however, there is no report of a functional connection between XPO5 and thyroid cancer incidence.

\section{Conclusions}

We note significant developments and progress in research to identify prognostic molecular factors in PTC, the knowledge of which would significantly facilitate the estimation of disease course; however, the results obtained to date do not allow any clear determination of the impact of the changes in a particular gene as a key factor in the development and prognosis of PTC. Further research is warranted to fully characterize the pathogenesis of PTC and the genetic contribution to this disease.

Author Contributions: Conceptualization, K.H., A.K. (Artur Kowalik) and A.K. (Aldona Kowalska); writing —original draft preparation, K.H.; writing—review and editing, A.K. (Artur Kowalik) and A.K. (Aldona Kowalska).

Funding: This research was funded by Jan Kochanowski University (JKU), Kielce (grant number 615566).

Conflicts of Interest: The authors declare no conflict of interest.

\section{References}

1. Bray, F.; Ferlay, J.; Soerjomataram, I.; Siegel, R.L.; Torre, L.A.; Jemal, A. Global cancer statistics 2018: GLOBOCAN estimates of incidence and mortality worldwide for 36 cancers in 185 countries. CA A Cancer J. Clin. 2018, 68, 394-424. [CrossRef] [PubMed]

2. World Health Organization (WHO) Classification. Available online: http://www.pathologyoutlines.com/ topic/thyroidwho.html (accessed on 29 April 2019). 
3. Nosé, V. Familial thyroid cancer: A review. Mod. Pathol. 2011, 24 (Suppl. 2), S19-S33.

4. Khan, A.; Smellie, J.; Nutting, C.; Harrington, K.; Newbold, K. Familial nonmedullary thyroid cancer: A review of the genetics. Thyroid 2010, 20, 795-801. [CrossRef] [PubMed]

5. Moses, W.; Weng, J.; Kebebew, E. Prevalence, clinicopathologic features, and somatic genetic mutation profile in familial versus sporadic nonmedullary thyroid cancer. Thyroid 2011, 21, 367-371. [CrossRef] [PubMed]

6. Pitoia, F.; Cross, G.; Salvai, M.E.; Abelleira, E.; Niepomniszcze, H. Patients with familial non-medullary thyroid cancer have an outcome similar to that of patients with sporadic papillary thyroid tumors. Arq. Bras. Endocrinol. Metabol. 2011, 55, 219-223. [CrossRef]

7. El Lakis, M.; Giannakou, A.; Nockel, P.J.; Wiseman, D.; Gara, S.K.; Patel, D.; Sater, Z.A.; Kushchayeva, Y.Y.; Klubo-Gwiezdzinska, J.; Nilubol, N.; et al. Do patients with familial nonmedullary thyroid cancer present with more aggressive disease? Implications for initial surgical treatment. Surgery 2019, 165, 50-57. [CrossRef]

8. Ito, Y.; Hirokawa, M.; Higashiyama, T.; Kihara, M.; Tomoda, C.; Takamura, Y.; Kobayashi, K.; Miya, A.; Miyauchi, A. Biological Behavior of Papillary Carcinoma of the Thyroid Including Squamous Cell Carcinoma Components and Prognosis of Patients Who Underwent Locally Curative Surgery. J. Thyroid Res. 2015, 2015, 230282. [CrossRef]

9. Pereira, J.S.; da Silva, J.G.; Tomaz, R.A.; Pinto, A.E.; Bugalho, M.J.; Leite, V.; Cavaco, B.M. Identification of a novel germline FOXE1 variant in patients with familial non-medullary thyroid carcinoma (FNMTC). Endocrine 2015, 49, 204-214. [CrossRef]

10. Guilmette, J.; Nosé, V. Hereditary and familial thyroid tumours. Histopathology 2018, 72, 70-81. [CrossRef]

11. Pal, T.; Vogl, F.D.; Chappuis, P.O.; Tsang, R.; Brierley, J.; Renard, H.; Sanders, K.; Kantemiroff, T.; Bagha, S.; Goldgar, D.E.; et al. Increased Risk for Nonmedullary Thyroid Cancer in the First Degree Relatives of Prevalent Cases of Nonmedullary Thyroid Cancer: A Hospital-Based Study. J. Clin. Endocrinol. Metab. 2001, 86, 5307-5312. [CrossRef]

12. Hemminki, K.; Dong, C. Familial relationships in thyroid cancer by histo-pathological type. Int. J. Cancer 2000, 85, 201-205. [CrossRef]

13. Ron, E.; Kleinerman, R.A.; LiVolsi, V.A.; Fraumeni, J.F., Jr. Familial Nonmedullary Thyroid Cancer. OCL 1991, 48, 309-311. [CrossRef] [PubMed]

14. Cetta, F.; Chiappetta, G.; Melillo, R.M.; Petracci, M.; Montalto, G.; Santoro, M.; Fusco, A. The ret/ptc1 oncogene is activated in familial adenomatous polyposis-associated thyroid papillary carcinomas. J. Clin. Endocrinol. Metab. 1998, 83, 1003-1006. [CrossRef] [PubMed]

15. Cetta, F.; Montalto, G.; Gori, M.; Curia, M.C.; Cama, A.; Olschwang, S. Germline Mutations of the APC Gene in Patients with Familial Adenomatous Polyposis-Associated Thyroid Carcinoma: Results from a European Cooperative. J. Clin. Endocrinol. Metab. 2000, 85, 286-292. [PubMed]

16. Cetta, F.; Pelizzo, M.R.; Curia, M.C.; Barbarisi, A. Genetics and clinicopathological findings in thyroid carcinomas associated with familial adenomatous polyposis. Am. J. Pathol. 1999, 155, 7-9. [CrossRef]

17. Bell, B.; Mazzaferri, E.L. Familial adenomatous polyposis (Gardner's syndrome) and thyroid carcinoma. A case report and review of the literature. Dig. Dis. Sci. 1993, 38, 185-190. [CrossRef] [PubMed]

18. Camiel, M.R.; Mulé, J.E.; Alexander, L.L.; Benninghoff, D.L. Association of Thyroid Carcinoma with Gardner's Syndrome in Siblings. N. Engl. J. Med. 1968, 278, 1056-1058. [CrossRef]

19. Haggitt, R.C.; Reid, B.J. Hereditary gastrointestinal polyposis syndromes. Am. J. Surg. Pathol. 1986, 10, 871-887. [CrossRef]

20. Mallory, S.B. Cowden syndrome (multiple hamartoma syndrome). Dermatol. Clin. 1995, 13, 27-31. [CrossRef]

21. Stratakis, C.A.; Courcoutsakis, N.A.; Abati, A.; Filie, A.; Doppman, J.L.; Carney, J.A.; Shawker, T. Thyroid gland abnormalities in patients with the syndrome of spotty skin pigmentation, myxomas, endocrine overactivity, and schwannomas (Carney complex). J. Clin. Endocrinol. Metab. 1997, 82, 2037-2043. [CrossRef]

22. Yu, C.E.; Oshima, J.; Fu, Y.H.; Wijsman, E.M.; Hisama, F.; Alisch, R.; Matthews, S.; Nakura, J.; Miki, T.; Ouais, S.; et al. Positional cloning of the Werner's syndrome gene. Science 1996, 272, 258-262. [CrossRef] [PubMed]

23. Vriens, M.R.; Suh, I.; Moses, W.; Kebebew, E. Clinical features and genetic predisposition to hereditary nonmedullary thyroid cancer. Thyroid 2009, 19, 1343-1349. [CrossRef] [PubMed]

24. Peiling Yang, S.; Ngeow, J. Familial non-medullary thyroid cancer: Unraveling the genetic maze. Endocr. Relat. Cancer 2016, 23, R577-R595. [CrossRef] [PubMed] 
25. Griffith, C.C.; Seethala, R.R. Familial non-medullary thyroid cancer: An update on the genetic and pathologic features. Diagn. Histopathol. 2016, 22, 101-107. [CrossRef]

26. Son, H.-Y.; Hwangbo, Y.; Yoo, S.-K.; Im, S.-W.; Yang, S.D.; Kwak, S.-J.; Park, M.S.; Kwak, S.H.; Cho, S.W.; Ryu, J.S.; et al. Genome-wide association and expression quantitative trait loci studies identify multiple susceptibility loci for thyroid cancer. Nat. Commun. 2017, 8, 15966. [CrossRef] [PubMed]

27. Saenko, V.A.; Rogounovitch, T.I. Genetic Polymorphism Predisposing to Differentiated Thyroid Cancer: A Review of Major Findings of the Genome-Wide Association Studies. Endocrinol. Metab. (Seoul) 2018, 33, 164-174. [CrossRef] [PubMed]

28. Hwangbo, Y.; Park, Y.J. Genome-Wide Association Studies of Autoimmune Thyroid Diseases, Thyroid Function, and Thyroid Cancer. Endocrinol. Metab. 2018, 33, 175-184. [CrossRef]

29. Jendrzejewski, J.; Liyanarachchi, S.; Nagy, R.; Senter, L.; Wakely, P.E.; Thomas, A.; Nabhan, F.; He, H.; Li, W.; Sworczak, K.; et al. Papillary Thyroid Carcinoma: Association Between Germline DNA Variant Markers and Clinical Parameters. Thyroid 2016, 26, 1276-1284. [CrossRef]

30. Rogounovitch, T.I.; Bychkov, A.; Takahashi, M.; Mitsutake, N.; Nakashima, M.; Nikitski, A.V.; Hayashi, T.; Hirokawa, M.; Ishigaki, K.; Shigematsu, K.; et al. The common genetic variant rs944289 on chromosome $14 \mathrm{q} 13.3$ associates with risk of both malignant and benign thyroid tumors in the Japanese population. Thyroid 2015, 25, 333-340. [CrossRef]

31. Wang, Y.; He, H.; Liyanarachchi, S.; Genutis, L.K.; Li, W.; Yu, L.; Phay, J.E.; Shen, R.; Brock, P.; de la Chapelle, A. The role of SMAD3 in the genetic predisposition to papillary thyroid carcinoma. Genet. Med. 2018, 20, 927-935. [CrossRef]

32. Pinto, A.E.; Silva, G.L.; Henrique, R.; Menezes, F.D.; Teixeira, M.R.; Leite, V.; Cavaco, B.M. Familial vs. Sporadic Papillary Thyroid Carcinoma: A Matched-Case Comparative Study Showing Similar Clinical/Prognostic Behaviour. Eur. J. Endocrinol. 2014, 170, 321-327. [CrossRef] [PubMed]

33. Rutter, M.M.; Jha, P.; Schultz, K.A.P.; Sheil, A.; Harris, A.K.; Bauer, A.J.; Field, A.L.; Geller, J.; Hill, D.A. DICER1 Mutations and Differentiated Thyroid Carcinoma: Evidence of a Direct Association. J. Clin. Endocrinol. Metab. 2016, 101, 1-5. [CrossRef] [PubMed]

34. Wasserman, J.D.; Sabbaghian, N.; Fahiminiya, S.; Chami, R.; Mete, O.; Acker, M.; Wu, M.K.; Shlien, A.; de Kock, L.; Foulkes, W.D. DICER1 Mutations Are Frequent in Adolescent-Onset Papillary Thyroid Carcinoma. J. Clin. Endocrinol. Metab. 2018, 103, 2009-2015. [CrossRef] [PubMed]

35. He, H.; Bronisz, A.; Liyanarachchi, S.; Nagy, R.; Li, W.; Huang, Y.; Akagi, K.; Saji, M.; Kula, D.; Wojcicka, A.; et al. SRGAP1 is a candidate gene for papillary thyroid carcinoma susceptibility. J. Clin. Endocrinol. Metab. 2013, 98, E973-E980. [CrossRef] [PubMed]

36. Gara, S.K.; Jia, L.; Merino, M.J.; Agarwal, S.K.; Zhang, L.; Cam, M.; Patel, D.; Kebebew, E. Germline HABP2 Mutation Causing Familial Nonmedullary Thyroid Cancer. N. Engl. J. Med. 2015, 373, 448-455. [CrossRef] [PubMed]

37. Alzahrani, A.S.; Murugan, A.K.; Qasem, E.; Al-Hindi, H. HABP2 Gene Mutations Do Not Cause Familial or Sporadic Non-Medullary Thyroid Cancer in a Highly Inbred Middle Eastern Population. Thyroid 2016, 26, 667-671. [CrossRef] [PubMed]

38. Kowalik, A.; Gassior-Perczak, D.; Gromek, M.; Siołek, M.; Walczyk, A.; Pałyga, I.; Chłopek, M.; Kopczyński, J.; Mężyk, R.; Kowalska, A.; et al. The p.G534E variant of HABP2 is not associated with sporadic papillary thyroid carcinoma in a Polish population. Oncotarget 2017, 8, 58304-58308. [CrossRef] [PubMed]

39. Wójcicka, A.; Czetwertyńska, M.; Świerniak, M.; Długosińska, J.; Maciąg, M.; Czajka, A.; Dymecka, K.; Kubiak, A.; Kot, A.; Płoski, R.; et al. Variants in the ATM-CHEK2-BRCA1 axis determine genetic predisposition and clinical presentation of papillary thyroid carcinoma. Genes Chrom. Cancer 2014, 53, 516-523. [CrossRef]

40. Siołek, M.; Cybulski, C.; Gąsior-Perczak, D.; Kowalik, A.; Kozak-Klonowska, B.; Kowalska, A.; Chłopek, M.; Kluźniak, W.; Wokołorczyk, D.; Pałyga, I.; et al. CHEK2 mutations and the risk of papillary thyroid cancer. Int. J. Cancer 2015, 137, 548-552. [CrossRef]

41. Dombernowsky, S.L.; Weischer, M.; Allin, K.H.; Bojesen, S.E.; Tybjjrg-Hansen, A.; Nordestgaard, B.G. Risk of Cancer by ATM Missense Mutations in the General Population. JCO 2008, 26, 3057-3062. [CrossRef]

42. Akulevich, N.M.; Saenko, V.A.; Rogounovitch, T.I.; Drozd, V.M.; Lushnikov, E.F.; Ivanov, V.K.; Mitsutake, N.; Kominami, R.; Yamashita, S. Polymorphisms of DNA damage response genes in radiation-related and sporadic papillary thyroid carcinoma. Endocr. Relat. Cancer 2009, 16, 491-503. [CrossRef] [PubMed] 
43. Gu, Y.; Yu, Y.; Ai, L.; Shi, J.; Liu, X.; Sun, H.; Liu, Y. Association of the ATM gene polymorphisms with papillary thyroid cancer. Endocrine 2014, 45, 454-461. [CrossRef] [PubMed]

44. Germline Alterations in RASAL1 in Cowden Syndrome Patients Presenting with Follicular Thyroid Cancer and in Individuals with Apparently Sporadic Epithelial Thyroid Cancer. Available online: Https://www.ncbi. nlm.nih.gov/pmc/articles/PMC5393485/ (accessed on 2 June 2019).

45. A Germline Mutation in SRRM2, a Splicing Factor Gene, is Implicated in Papillary Thyroid Carcinoma Predisposition-Semantic Scholar. Available online: Https://www.semanticscholar.org/paper/A-germlinemutation-in-SRRM2\%2C-a-splicing-factor-is-Tomsic-He/497dc1da6155e4d729e5a8c77f9d5863a676fb2a (accessed on 2 June 2019).

46. Ryu, R.A.; Tae, K.; Min, H.J.; Jeong, J.H.; Cho, S.H.; Lee, S.H.; Ahn, Y.H. XRCC1 Polymorphisms and Risk of Papillary Thyroid Carcinoma in a Korean Sample. J. Korean Med. Sci. 2011, 26, 991-995. [CrossRef] [PubMed]

47. Ngan, E.S.W.; Lang, B.H.H.; Liu, T.; Shum, C.K.Y.; So, M.-T.; Lau, D.K.C.; Leon, T.Y.Y.; Cherny, S.S.; Tsai, S.Y.; Lo, C.-Y.; et al. A germline mutation (A339V) in thyroid transcription factor-1 (TITF-1/NKX2.1) in patients with multinodular goiter and papillary thyroid carcinoma. J. Natl. Cancer Inst. 2009, 101, 162-175. [CrossRef] [PubMed]

48. Cantara, S.; Pisu, M.; Frau, D.V.; Caria, P.; Dettori, T.; Capezzone, M.; Capuano, S.; Vanni, R.; Pacini, F. Telomere Abnormalities and Chromosome Fragility in Patients Affected by Familial Papillary Thyroid Cancer. J. Clin. Endocrinol. Metab. 2012, 97, E1327-E1331. [CrossRef] [PubMed]

49. Jendrzejewski, J.; He, H.; Radomska, H.S.; Li, W.; Tomsic, J.; Liyanarachchi, S.; Davuluri, R.V.; Nagy, R.; de la Chapelle, A. The polymorphism rs 944289 predisposes to papillary thyroid carcinoma through a large intergenic noncoding RNA gene of tumor suppressor type. Proc. Natl. Acad. Sci. USA 2012, 109, 8646-8651. [CrossRef] [PubMed]

50. Matsuse, M.; Takahashi, M.; Mitsutake, N.; Nishihara, E.; Hirokawa, M.; Kawaguchi, T.; Rogounovitch, T.; Saenko, V.; Bychkov, A.; Suzuki, K.; et al. The FOXE1 and NKX2-1 loci are associated with susceptibility to papillary thyroid carcinoma in the Japanese population. J. Med. Genet. 2011, 48, 645-648. [CrossRef] [PubMed]

51. Bychkov, A.; Saenko, V.; Nakashima, M.; Mitsutake, N.; Rogounovitch, T.; Nikitski, A.; Orim, F.; Yamashita, S. Patterns of FOXE1 Expression in Papillary Thyroid Carcinoma by Immunohistochemistry. Thyroid 2013, 23, 817-828. [CrossRef] [PubMed]

52. He, H.; Li, W.; Liyanarachchi, S.; Jendrzejewski, J.; Srinivas, M.; Davuluri, R.V.; Nagy, R.; de la Chapelle, A. Genetic predisposition to papillary thyroid carcinoma: Involvement of FOXE1, TSHR, and a novel lincRNA gene, PTCSC2. J. Clin. Endocrinol. Metab. 2015, 100, E164-E172. [CrossRef] [PubMed]

53. He, H.; Li, W.; Liyanarachchi, S.; Srinivas, M.; Wang, Y.; Akagi, K.; Wang, Y.; Wu, D.; Wang, Q.; Jin, V.; et al. Multiple functional variants in long-range enhancer elements contribute to the risk of SNP rs965513 in thyroid cancer. Proc. Natl. Acad. Sci. USA 2015, 112, 6128-6133. [CrossRef] [PubMed]

54. Wang, Y.; He, H.; Li, W.; Phay, J.; Shen, R.; Yu, L.; Hancioglu, B.; de la Chapelle, A. MYH9 binds to lncRNA gene PTCSC2 and regulates FOXE1 in the 9q22 thyroid cancer risk locus. Proc. Natl. Acad. Sci. USA 2017, 114, 474-479. [CrossRef] [PubMed]

55. Etienne-Manneville, S. Cdc42-The Centre of Polarity. J. Cell Sci. 2004, 117, 1291-1300. [CrossRef] [PubMed]

56. Sahasrabudhe, R.; Stultz, J.; Williamson, J.; Lott, P.; Estrada, A.; Bohorquez, M.; Palles, C.; Polanco-Echeverry, G.; Jaeger, E.; Martin, L.; et al. The HABP2 G534E variant is an unlikely cause of familial non-medullary thyroid cancer. J. Clin. Endocrinol. Metab. 2016, 10, 1098-1103. [CrossRef] [PubMed]

57. RASAL1 RAS Protein Activator Like 1 [Homo Sapiens (Human)]-Gene. Available online: Https://www.ncbi. nlm.nih.gov/gene/8437 (accessed on 1 June 2019).

58. Liu, D.; Yang, C.; Bojdani, E.; Murugan, A.K.; Xing, M. Identification of RASAL1 as a Major Tumor Suppressor gene in Thyroid Cancer. J. Natl. Cancer Inst. 2013, 105, 1617-1627. [CrossRef] [PubMed]

59. Mazzaferri, E.L.; Jhiang, S.M. Long-term impact of initial surgical and medical therapy on papillary and follicular thyroid cancer. Am. J. Med. 1994, 97, 418-428. [CrossRef]

60. Jegerlehner, S.; Bulliard, J.-L.; Aujesky, D.; Rodondi, N.; Germann, S.; Konzelmann, I.; Chiolero, A. Overdiagnosis and overtreatment of thyroid cancer: A population-based temporal trend study. PLoS ONE 2017, 12. [CrossRef] 
61. Świerniak, M.; Wójcicka, A.; Czetwertyńska, M.; Długosińska, J.; Stachlewska, E.; Gierlikowski, W.; Kot, A.; Górnicka, B.; Koperski, Ł.; Bogdańska, M.; et al. Association between GWAS-Derived rs966423 Genetic Variant and Overall Mortality in Patients with Differentiated Thyroid Cancer. Clin. Cancer Res. 2016, 22, 1111-1119. [CrossRef]

62. Wei, W.-J.; Lu, Z.-W.; Wang, Y.; Zhu, Y.-X.; Wang, Y.-L.; Ji, Q.-H. Clinical significance of papillary thyroid cancer risk loci identified by genome-wide association studies. Cancer Genet. 2015, 208, 68-75. [CrossRef]

63. Dong, G.; Zhang, R.; Xu, J.; Guo, Y. Association between microRNA polymorphisms and papillary thyroid cancer susceptibility. Int. J. Clin. Exp. Pathol. 2015, 8, 13450-13457.

64. Jazdzewski, K.; Murray, E.L.; Franssila, K.; Jarzab, B.; Schoenberg, D.R.; de la Chapelle, A. Common SNP in pre-miR-146a decreases mature miR expression and predisposes to papillary thyroid carcinoma. Proc. Natl. Acad. Sci. USA 2008, 105, 7269-7274. [CrossRef]

65. Wen, J.; Gao, Q.; Wang, N.; Zhang, W.; Cao, K.; Zhang, Q.; Chen, S.; Shi, L. Association of microRNA-related gene XPO5 rs11077 polymorphism with susceptibility to thyroid cancer. Medicine (Baltimore) 2017, 96, e6351. [CrossRef] [PubMed]

(C) 2019 by the authors. Licensee MDPI, Basel, Switzerland. This article is an open access article distributed under the terms and conditions of the Creative Commons Attribution (CC BY) license (http://creativecommons.org/licenses/by/4.0/). 